\title{
O SIGNIFICADO DA EXPERIÊNCIA ESCOLAR PARA SEGMENTOS DAS CAMADAS MÉDIAS
}

\author{
ISABEL LELIS \\ Programa de Pós-Graduação em Educação da \\ Pontifícia Universidade Católica do Rio de Janeiro \\ isabell@edu.puc-rio.br
}

RESUMO

Este texto tem como objetivo revelar o sentido da experiência escolar para jovens de camadas médias, alunos de uma instituição privada confessional, da zona sul da cidade do Rio de Janeiro. Algumas questões serviram de ponto de partida para a pesquisa realizada de $200 \mathrm{I}$ a 2003: como alunos com esse perfil socioeconômico e educacional constroem o seu ofício de estudante? Como articulam as relações com professores e colegas? Que relações estabelecem com as práticas de avaliação e os processos de ensinar e aprender? Relações instrumentais? Relações as quais permitem que os significados de seus grupos de referência aflorem? Que modelos de socialização são veiculados por essas escolas? O foco de análise apoiou-se em algumas das condições de produção e expressão do ofício do aluno como a caracterização socioeconômica das famílias, a trajetória escolar dos estudantes ao longo do ensino fundamental, o papel do estudo em suas vidas e práticas culturais e o lazer dos jovens.

ALUNO - SOCIOLOGIA DO ESTUDANTE - RELAÇÕES PROFESSOR-ALUNO - PRÁTICA DE ENSINO

\section{ABSTRACT}

THE MEANING OF SCHOOL EXPERIENCE FOR MIDDLE CLASS SEGMENTS. The objective of this text is to disclose the meaning of school education for middle class youngsters who are students of a private confessional institution in the South zone of Rio de Janeiro city. Some questions have served as the starting point for the research carried out from 2001 to 2003: How do students with this social, economic, and educational profile frame their role as students? How do they articulate their relationships with teachers and colleagues? What relationships do they establish with evaluation practices and teaching and learning processes? Instrumental relationships? Relationships that allow the meanings of their reference groups to emerge? What socialization models are transmitted by these schools? The focus of the analysis was based on some of the conditions of production and expression of the role of the student as a social and economic characterization of his/her family, the learning path of students along primary school, the role of study in their lives, and the cultural practices and leisure activities of youngsters.

STUDENT - STUDENT SOCIOLOGY - STUDENT TEACHER RELATION EDUCATIONAL PRACTICE 
Com o objetivo de conhecer como o jovem de camadas médias vive a experiência escolar, nas estratégias que manifesta como aluno, iniciamos em março de 200I uma pesquisa' em uma escola privada da zona sul da cidade do Rio de Janeiro.

Nossa intenção era a de verificar como adolescentes se relacionavam com as práticas escolares, com as tarefas cotidianas, tendo como hipótese o fato de que um conjunto de disposições nasce na família a partir dos investimentos feitos pelos pais na escolarização da prole.

Trata-se de estudo que dá continuidade à pesquisa coordenada por Zaia Brandão "Trajetórias escolares e processos de socialização", voltada para o conhecimento das práticas educacionais das camadas médias na transmissão do capital cultural e escolar a seus filhos.

Sendo ou não conscientes, as estratégias educativas desenvolvidas pelas famílias têm a capacidade de sedimentar habitus ${ }^{2}$, ajudando a entender como alunos se mobilizam diante dos estudos, das tarefas escolares, de suas preferências quanto aos estilos de ensinar dos professores etc.

Algumas questões serviram de ponto de partida para o estudo: como os alunos, filhos de camadas médias, imersos em escolas particulares constroem a experiência escolar? Como fabricam as relações com professores e com seus colegas? Que tipo de relação estabelecem com as práticas de avaliação e os processos de ensinar e aprender? Seriam relações instrumentais? Quais relações permitem que os significados culturais de seus grupos de referência aflorem? Que modelos de socialização são veiculados por essas escolas?

Com essas perguntas, a intenção era a de compreender o sentido da escolarização, que é pessoal e coletiva, e que confere ao aluno/ator a possibilidade de construir significados, efetuar escolhas, mover-se no interior da escola mediante um saber fazer, pois a escola não produz apenas qualificações e competências, ela contribui para que os indivíduos tenham disposições e atitudes (Dubet, Martuccelli, 1996), isto é, serem também sujeitos de sua própria educação.

I. "O ofício do aluno e o sentido da experiência escolar", pesquisa desenvolvida no Programa de Pós-Graduação da PUC-Rio, de 200 I a 2003, que contou com a participação dos alunos Alexandra de Oliveira Gomes, Cristiane Gomes de Oliveira, Eliane Santos da Silva, Luiz Otávio Neves Mattos, Paulo Roberto do Patrocínio Tonani e Thelma Polon, e foi financiada pelo Conselho Nacional de Desenvolvimento Científico e Tecnológico - CNPq.

2. Para Bourdieu (1997) o habitus é um "sistema adquirido de preferências, de princípios de visão e de divisão (o que chamamos comumente de gosto), de estruturas duradouras". 
O significado da experiência...

Mais ainda por se tratar de uma escola privada atendida por setores das camadas médias, interessava interrogar qual o peso das práticas escolares sobre a construção do ofício de estudante, sobre os modos de apreensão da experiência escolar ${ }^{3}$.

A opção por estudar a escola privada derivou da necessidade de aproximação do universo das camadas médias, pouco explorado ainda do ponto de vista de suas estratégias educativas, mas principalmente pela necessidade de torná-las mais visíveis em termos de seus estilos de vida, de seus projetos de escolarização. Sem desconhecer a diversidade interna dessas camadas, nosso movimento foi o de realizar a pesquisa em um tipo de escola freqüentada por esses segmentos: a escola de bairro, de pequeno porte, que oferece apenas o ensino fundamental.

Essa escolha permitiu a explicitação de relações entre padrões de vida de adolescentes de extratos médios e habitus escolar, o que em última análise vem contribuir para o adensamento das diferenciações que se processam no interior desse segmento no que se refere às desigualdades em termos de oportunidades escolares dessas camadas.

Alguns autores da sociologia da educação serviram de inspiração para a pesquisa e muito ajudaram na interpretação dos dados levantados. Entre eles, destacamos a contribuição de François Dubet e Danilo Martuccelli, de Bernard Charlot e de Phillippe Perrenoud pois cada um à sua maneira tem pensado as práticas sociais - familiares e escolares - e seus impactos sobre as disposições que jovens/estudantes incorporam, manifestam e sentem na escola e fora dela. Mas foi Perrenoud no seu livro O ofício do aluno e o sentido do trabalho escolar, quem sinalizou a necessidade de investirmos na pesquisa sobre o aprender a ser estudante:

Tratando-se do que se aprende pela prática para uma prática ulterior, existe um meio indireto: analisar o tipo de relações, de comunicações, de jogos interpessoais e organizacionais que se praticam na aula, o que pelo menos, dará uma idéia

3. Para Dubet e Martuccelli (1996), a experiência escolar é definida como o modo pelo qual os atores individuais e coletivos combinam as diversas lógicas de ação que estruturam o mundo escolar. Para os autores, as lógicas de ação - integração, estratégia e subjetivação - correspondem às três funções essenciais do sistema escolar: socialização, distribuição de competências e educação. 
do tipo de actores que a escola forma quanto às relações com o outro e na vida de uma organização. É claro, uma aprendizagem não nasce de uma prática excepcional. É pois, nas regularidades que é preciso separar as duráveis, as situações escolares que favorecem a formação de esquemas de ações e de interações relativamente estáveis e que, por um lado, possam ser transpostas para outras situações comparáveis, fora da escola ou após a escolaridade. (1994, p.32)

Se, no projeto original, a tendência era a de que o trabalho de campo se desenvolveria em duas escolas - uma considerada inovadora no sistema privado, que valoriza a realização pessoal dos estudantes, representativa de um modo mais interativo e afetivo de lidar com a escolarização e, outra, marcada como tradicional pela exigência e seleção intelectual -, o desenvolvimento da pesquisa sinalizou para o esforço de concentrar o estudo em uma única instituição. Essa redefinição foi assumida no processo de levantamento de dados e levou em consideração algumas exigências de caráter teórico-metodológico:

- a construção do objeto "ofício de aluno" implicou observação prolongada de disposições (práticas, atitudes, comportamentos) incorporadas pelos jovens, geradoras, por sua vez, de esquemas particulares aplicados em diferentes situações de ensino;

- a observação das práticas, por envolver um conjunto extenso de atividades (aulas em todas as disciplinas, atividades extra-classe, eventos, reuniões, festas, recreio etc.) seria difícil de ser realizada em mais de uma instituição;

- a construção dos instrumentos - observação, entrevista e questionário - exigiu a seleção de categorias de análise, a definição de conceitos, o mapeamento de questões, operações essas indispensáveis à elaboração e reelaboração de perguntas dos roteiros de entrevista e do questionário, bem como a sua realização e a interpretação dos dados.

\section{ESTRATÉGIAS METODOLÓGICAS}

O colégio Santa Margarida ${ }^{4}$, onde realizamos a pesquisa, está localizado na zona sul da cidade do Rio de Janeiro, em região com alta renda per capita,

4. O nome da instituição é fictício. 
O significado da experiência...

sendo os moradores do bairro atendidos por um conjunto de escolas privadas, escolas públicas e uma universidade particular de larga tradição na cidade e no país. Trata-se de uma instituição que enfrenta uma crise séria, provocada por um conjunto de fatores de natureza financeira e pedagógica, com repercussões sobre sua identidade. Essa crise tornou-se mais aguda nos dois últimos anos, levando a mudanças sucessivas de membros da coordenação pedagógica, perda de alunos, demissão de antigos professores e a redução do quadro de funcionários.

Em 200 I, no início da pesquisa, a instabilidade tomou conta da instituição com a saída de parte da equipe diretora, provocada por cisões no interior da congregação religiosa, mantenedora da escola. Nas palavras da orientadora pedagógica do colégio, naquele momento:

...eu acho que [a saída] reproduz um pouco a história da congregação, meio que uma briga de poder de idéias, de qual igreja vai prevalecer: é a de Leonardo Boff ou é a de Eugenio Salles... E isso resvala para o corpo docente... ao mesmo tempo em que é aberta, na questão metodológico-pedagógica, por outro lado, é uma escola mais fechada, menos politizada...

Se a orientação religiosa e pedagógica foi colocada em questão, o que importa destacar como indicador significativo é a evasão de alunos nos últimos cinco anos, com desdobramentos sobre a sua imagem ${ }^{5}$. A esse quadro, acrescente o fato da mudança na composição da clientela, hoje heterogênea, pois é constituída por setores empobrecidos das camadas médias e por uma pequena parcela das camadas populares, moradores de um parque proletário próximo à escola.

Para duas das professoras entrevistadas trata-se de uma instituição tentando livrar-se da imagem de ser uma escola que perdeu em qualidade de ensino por atender a alunos portadores de dificuldades de aprendizagem e de histórias de fracasso escolar.

Quanto ao universo pesquisado, a escolha recaiu sobre alunos de $8^{a}$ série uma vez que essa série foi uma das selecionadas pelo Sistema Nacional de Avaliação do Ensino Básico - Sab - na tarefa de avaliar a qualidade da escola e

5. A evasão intensificou-se de 200 I para 2002 e 2003 e foi da ordem de 10\% e 15\% em cada ano. 
do ensino brasileiro. Essa fase representa um momento importante da escolarização, especialmente para as famílias de camadas médias, o cumprimento de uma etapa para entrada no ensino médio com vistas ao enfrentamento do vestibular e conseqüente conquista de uma vaga no ensino superior.

Na tarefa de decifrarmos o ofício do aluno, a equipe concentrou-se em um primeiro momento na observação das práticas no interior da sala de aula - locus principal de análise - e nos espaços por onde circulavam os alunos (sala de informática, pátio do recreio, corredores) das duas turmas de 8 a série. Foram observadas aulas em todas as disciplinas que compunham o currículo escolar no sentido de apreender os estilos de ensinar dos professores e as respostas dadas pelos alunos quanto a esse aspecto.

Em nossa grade de observação, pensada a partir de alguns eixos, foram privilegiadas as rotinas na sala de aula, o uso do tempo pelo aluno e pelo professor, as estratégias desenvolvidas pelos alunos diante das tarefas propostas pelos professores, o lugar ocupado pela avaliação (provas, exercícios) para o aluno e o professor e suas repercussões no cotidiano escolar, as atitudes dos alunos em face das regras disciplinares, as formas de comunicação/relação entre alunos e entre alunos e professores. Essa observação foi intensiva, feita por membros da equipe e cobriu todos os tempos da grade curricular. Tinha como objetivo ainda obter informações prévias para a elaboração dos roteiros das entrevistas que seriam realizadas com os professores e do questionário a ser aplicado aos alunos.

Em 2002, a observação concentrou-se na sala de aula da única turma de $8^{a}$ série $^{6}$, mas foi ampliada para outros espaços como festas, eventos, reuniões pedagógicas, conselhos de classe, feiras etc. Paralelamente às observações, realizamos entrevistas com três coordenadoras pedagógicas e duas orientadoras educacionais do segundo segmento do ensino fundamental com a finalidade de mapear suas representações sobre o momento pelo qual passava a instituição, o projeto pedagógico da escola, as novas prioridades diante do trabalho pedagógico com a mudança da equipe. Realizamos também sete entrevistas com professores de diferentes disciplinas para conhecer suas representações sobre os comportamentos dos alunos, as relações diante das tarefas escolares, a mobilização em relação ao saber.

6. Em 2002, foi aberta uma única turma de $8^{a}$ série em razão da evasão de alunos de 200 I . 
O significado da experiência...

Finalmente nos valemos de um questionário construído pela equipe da pesquisa "Escolarização das elites", coordenada por Zaia Brandão, e que foi redimensionado com base no material colhido com as nossas observações. Esse questionário ${ }^{7}$ foi aplicado a 30 alunos da 8ª série de 2003 e sua elaboração levou em conta alguns eixos de análise: origem familiar, condições socioeconômicas das famílias, práticas culturais dos jovens, representações sobre a escola e seus professores, hábitos de estudo, desempenhos acadêmicos, trajetória escolar anterior, atividades de lazer, atividades extra-classe etc.

De posse de todo o material, iniciamos os cruzamentos entre dados provenientes das observações, dados originários das entrevistas e dos questionários, no intento de verificar as condições de realização do ofício do aluno e suas formas de expressão.

Para efeito deste artigo, serão consideradas algumas das condições necessárias à constituição do ofício do aluno como o perfil socioeconômico das famílias, o fluxo escolar desses alunos, o lugar que ocupa o estudo em seu cotidiano, bem como suas práticas culturais e atividades de lazer.

\section{OS ALUNOS E SUAS FAMÍLIAS}

Os alunos situam-se em uma faixa etária entre 14 e 16 anos, sendo 42\% do sexo feminino e 58\% do sexo masculino. Residem, na sua maioria, no próprio bairro em que está localizada a escola ou em bairros circunvizinhos como Jardim Botânico, Leblon, Lagoa entre outros.

As famílias possuem, na maioria, dois filhos (54\%), havendo I5\% de estudantes filhos únicos; $31 \%$ dos alunos têm dois ou mais irmãos. $\bigcirc$ fato de essas famílias terem limitado a sua prole representa uma estratégia de reprodução própria das camadas médias mais desprovidas de capital econômico e cultural, já mapeada pela literatura especializada, e uma condição para a constituição do ofício de estudante pois a forte restrição da fecundidade significa para esses grupos poderem investir em cada filho, garantindo o máximo possível de recursos com uma despesa menor.

Em que pese a ação dessas famílias para concentrar os recursos de que

7. Por opção da equipe, quatro desses questionários foram descartados devido ao preenchimento errado pelos alunos. 
dispõem na educação de poucos filhos, as falas das coordenadoras revelaram que as agendas dos alunos, antes muito sobrecarregadas de atividades extraclasse (cursos de língua, aulas de natação, de dança etc.), hoje encontram-se mais livres dadas as transformações do estilo de vida desses segmentos em processo de empobrecimento.

A situação não é prerrogativa desse grupo, mas atingiu os segmentos $A$ e B da população brasileira, especialmente em certos setores como o dos planos de saúde, do lazer e da educação dos filhos. Dados de pesquisa desenvolvida pelo Instituto Ipsos-Marplan ${ }^{8}$ revelaram que as grandes redes de idiomas, que tem franquias espalhadas por todo o país, viram diminuir seus consumidores (especialmente nas primeiras séries do ensino fundamental) sendo a retração da ordem de 15\% no número de alunos matriculados em 2002 em relação a 200 I. Espremidas entre o desemprego e a deterioração dos salários de um lado e a disparada dos preços dos serviços e tarifas públicas, as camadas médias vêem-se obrigadas a redimensionar seus gastos, inclusive os considerados sagrados como a escolarização dos filhos.

Nessa direção, valeria perguntar: considerando que as atividades extraclasse (aulas de língua, dança, esportes variados) teriam a função, entre outras, de promover a aprendizagem do uso do tempo como um empreendimento partilhado entre pais e filhos (Nogueira, | 99|), que conseqüências advêm para o aluno pela restrição dessas atividades? Que outras atividades preencheriam o uso do tempo fora do espaço escolar? Essas novas atividades têm impactado a forma de viverem o ofício de aluno? De que modo?

Relacionado a essa situação, há um outro dado que, de certa forma, vem relativizar achados da literatura francesa ${ }^{9}$ dos últimos anos: uma diminuição do monitoramento, pelas famílias, das tarefas escolares dos filhos. Se é verdade que os dados revelados pelos questionários apontam o fato de que o rendi-

8. A referida pesquisa adotou o Critério de Classificação Econômica Brasil, dividindo a sociedade por classes econômicas (A, B, C, D e E), no sentido de avaliar o potencial de compra das famílias urbanas. A renda média familiar da classe A, em 2002, era de $R$ \$ 4.696 (Al) a R $\$ 2.869$ (A2). Na classe B, a renda média familiar era de $\mathrm{R} \$ 1.784$ (BI) a $\mathrm{R} \$ 1.158$ (B2), segundo dados da Folha de S.Paulo, I5. 7. 2003.

9. Devem ser destacados o valor e a importância, para o campo da sociologia da escolarização, das revisões de literatura, produzidas por Maria Alice Nogueira, que permitiram o acesso ao estudo da relação entre famílias de camadas médias e escola. 
mento escolar freqüentemente é tema de conversa para $42 \%$ dos alunos e, algumas vezes, para 46\%, em nossas observações diárias houve grande incidência de alunos que faltaram às aulas, esqueceram o material didático, não cumpriram com as tarefas solicitadas, em especial, o dever de casa. Para algumas professoras, é comum o hábito de dormir tarde entre os adolescentes usuários da internet, com prejuízos da pontualidade às aulas. As razões para tais comportamentos estariam na sobrecarga de trabalho dos pais, na diminuição do tempo de convivência e conseqüente dificuldade de monitoramento dos hábitos de estudo, como afirmaram algumas das coordenadoras entrevistadas. Se essa situação não chega a configurar um quadro de falta de participação nos processos de escolarização dos filhos, ela é reveladora da crescente participação das mulheres no mercado de trabalho e seus reflexos no trabalho pedagógico doméstico de reforço da aprendizagem escolar.

Quando passamos ao tipo de família ao qual pertencem os alunos, verificamos que 38\% são nucleares, sendo que entre as demais predominam situações de unidades domésticas onde moram mães e filhos (56\%) e I 2\% de famílias recompostas, fruto de duas ou mais uniões de um ou de ambos os parceiros. Essa característica implica uma diversidade que resulta em estilos de vida peculiares, com formas de sociabilidade específicas, o que redunda em modos distintos de relacionamento entre pais e filhos, inclusive no que diz respeito ao monitoramento da escolarização (Romanelli, 2002, p.249).

$\bigcirc$ impacto das novas configurações familiares sobre a escolarização dos filhos, segundo depoimentos de professores, leva ao freqüente esquecimento de livros ou cadernos "na casa do pai" quando de visita ocasional, com repercussões sobre o desempenho do aluno na sala de aula. Como fato que se generaliza, esse dado vem sugerir novas formas de acompanhamento da vida escolar dos filhos, diversas daquelas realizadas por famílias nucleares, constituídas por pai, mãe e filhos.

Com relação ao perfil socioeconômico, verificamos que 62\% dos pais possuem diploma de ensino superior, sendo que surpreendentemente esse número cresce quando passamos às mães (73\%). Apenas dois alunos assinalaram ser baixa a escolaridade final dos pais ( ${ }^{\mathrm{a}}$ a $4^{\mathrm{a}}$ série em um caso e $5^{\mathrm{a}}$ a $8^{\mathrm{a}}$ série em outro caso) e mesmo nula, caso de uma mãe de um aluno. Foi, contudo, significativo o fato de $27 \%$ dos alunos desconhecerem até que série o pai estudou, contra $12 \%$ que não sabem o grau de escolaridade da mãe. $\bigcirc$ fato de termos encontrado este perfil sugere algumas possibilidades de inter- 
pretação. Uma delas pode estar nos novos arranjos familiares que ainda têm garantida a maior presença da mãe na vida do filho e, portanto, o reconhecimento de sua ocupação, uma vez que a maioria dos alunos vive com a mãe e irmãos. Uma outra razão pode estar no baixo capital cultural das famílias desses alunos, expresso na falta de reconhecimento da importância do nível de escolaridade dos pais e, por conseguinte, do lugar que ocupam na estratificação sociocupacional. De qualquer modo, o fato de um elevado número de alunos ter afirmado não saber até que série o pai estudou torna problemática uma análise precisa, dificultando qualquer afirmação mais pontual.

Quando passamos a analisar a principal atividade econômica exercida pelos pais, o que encontramos foi um leque diversificado de ocupações no interior do que estamos chamando "camadas médias". Sem pretender discutir neste momento abordagens metodológicas que tratam dessa categoria sociológica, o que os dados nos revelam é a presença de uma classe média constituída por advogados, médicos, engenheiros e arquitetos, pais de $42 \%$ dos estudantes e por artistas (artista gráfico, fotógrafo, músico, artista plástico), pais de 17\% dos alunos. Trata-se de frações que desempenham atividades de natureza técnica, social e cultural e que constituem "o núcleo duro da classe média"(Nogueira, 1995).

No interior do que podemos chamar como média classe média/baixa classe média, encontramos 14\% dos pais exercendo funções como a de funcionário público, bancário e economiário, e 7\% de por pais cujas ocupações são de baixo prestígio, caso de um porteiro e um motorista. No outro extremo dessa segmentação sociocupacional, há I4\% de pais ligados a atividades empresariais e comerciais.

No caso das mães, o quadro revela algumas diferenças, entre as quais um número menor de mães (27\%), se comparado aos pais, exercendo ocupações de nível técnico superior (advogada, arquiteta, economista e analista de sistemas) e 20\% em ocupações ligadas à arte (artista, produtora de arte, desenhista industrial, publicitária, mosaicista) e ao esporte. Mesmo se considerarmos que este último grupo pode ou não ser possuidor de título escolar, vale para os dois subgrupos a idéia de que essas frações atribuem aos fatores socioculturais (estilo de vida, natureza da ocupação, bairro onde mora) um peso significativo ao conteúdo da experiência escolar dos filhos.

Como dado sugestivo, encontramos uma variabilidade maior de ocupações entre as mães se comparada à dos pais, senão vejamos: 13\% dos estudantes têm mães exercendo atividades ligadas a serviços sociais como o ma- 
O significado da experiência...

gistério, enfermagem, psicologia; 13\% das mães dedicam-se a atividades do lar; 13\% delas exercem ocupações de técnico de nível médio como balconista, vendedora, comerciária. Trata-se de profissões de caráter assistencial no primeiro caso, muito procuradas há algumas décadas por segmentos das camadas populares e médias na busca por uma mobilidade social ascendente.

Em que pese o fato de haver famílias que possuíam algum curso superior, foi sugestiva a fala de uma coordenadora ao mapear esse perfil:

...comparando com a escola Edem, os pais desse colégio não se caracterizam por serem da elite intelectual; são pais que se caracterizam pela relação custobenefício "eu pago, quero ter qualidade de educação, retorno". São pessoas mais individualistas e competitivas. Em uma olimpíada, tinha pai incitando o filho a competir para ganhar. São pessoas com menos comprometimento social e político. Há poucos que fogem a esta caracterização. A grande maioria não percebe a riqueza do trabalho que a escola realiza. Os pais têm uma visão pragmática, valorizam uma orientação religiosa... uma escola mais enquadradinha, mais organizadinha... Há pais que já tiveram a seguinte postura: quem foi esse professor que reprovou meu filho? Meu filho não vai passar de ano? Eu pago essa escola para meu filho passar de ano! (Coordenadora C)

Para outro professor, as famílias desconhecem tudo sobre educação, não estão preocupadas se os filhos estão aprendendo, mas que sejam aprovados ao final do ano. Trata-se de que pais que no discurso valorizam o estudo, mas na prática não manifestam a disposição de acompanhar a escolarização dos filhos, não têm tempo. Esses setores aproximar-se-iam, segundo Nogueira,

...dos pequenos comerciantes pois apelam com freqüência ao ensino privado, seja para se assegurar de um acompanhamento mais estreito e mais personalizado do aluno pela escola, seja para se esquivar de uma orientação escolar anterior estimada desfavorável e da qual discorda. Porém, diferem deles no que diz respeito às decisões escolares: contestam-nas sem hesitação todas as vezes em que estas se contrapõem a seus projetos escolares, dispostos para tanto a até mesmo mudar de estabelecimento escolar. E para isso contam com todo um patrimônio de informações sobre o modo de funcionamento real do aparelho escolar. (1991, p. 102) 
Para além desse tipo de comportamento, marcado pela valorização do resultado escolar e não pela qualidade dos processos de ensino-aprendizagem, algumas questões se põem: qual o significado da experiência escolar para o aluno quando a família tem para com a escola uma visão economicista do tipo custo-benefício? Qual a força o habitus familiar na constituição e desenvolvimento do hábito de estudo para essa clientela? De um modo ou de outro, o que os dados sugerem é o fato de essa escola ser hoje uma alternativa para segmentos empobrecidos das camadas médias, inclusive por cobrar anuidades mais baixas do que outras instituições situadas no mesmo bairro ${ }^{10}$.

\section{A TRAJETÓRIA NO ENSINO FUNDAMENTAL}

Ao analisarmos a trajetória escolar desses alunos desde a classe de alfabetização um dado chama a atenção: a trajetória ao longo do ensino fundamental é contínua; não revela a presença formal da reprovação, o que não significa que o fluxo pelas séries tenha plena fluência. Explicando melhor, apenas seis alunos em 32 (I8\%) estão na escola desde o pré-escolar, tendo I I alunos passado por pelos menos três ou mais escolas particulares antes de ingressar na instituição investigada. Isso significa uma exposição a experiências escolares e pedagógicas diversificadas e mais, expressa a presença ativa das famílias na busca por adequar seus projetos educativos às necessidades individuais de seus filhos. Mas há também um outro elemento que se articula a essa dinâmica: o número elevado de alunos (37\%) que entrou na $7^{\text {a }}$ ou $8^{a}$ série, isto é, chegou à escola para finalizar a etapa do ensino fundamental. As razões para tal podem ser variadas e vão desde a "representação" de uma escola mais fraca quanto à exigência acadêmica até a ação clandestina das famílias para evitar a reprovação.

Esses dados são provocadores na medida em que sinalizam para percursos contínuos, não erráticos de setores das camadas médias, o que não quer dizer que sejam lineares e sem rupturas. Afirmar o sucesso da escola privada tout court diante do insucesso generalizado da escola pública pela via dos índices de reprovação é temerário, uma vez que o sucesso não pode ser medido apenas pelo desempenho acadêmico final, expresso em classificações sob for-

$\overline{\text { 10. Foi significativo o fato }}$ de termos encontrado em uma turma de 32 alunos, 12 com bolsa parcial. 
ma de notas ou conceitos. Há um conjunto de estratégias invisíveis acionadas pelos pais que encobrem o rendimento escolar real dos filhos em determinadas escolas privadas e, portanto, seus processos de ensino e aprendizagem, os quais precisam ser investigados pelos pesquisadores, como, por exemplo, a movimentação por entre escolas no decorrer do ensino fundamental.

De um modo ou de outro o que essas trajetórias revelam é a presença de um percurso do tipo "todo privado", só quebrado por um número reduzido de alunos (19\%) que indicou a escola pública como instituição freqüentada antes da entrada no ensino fundamental, caso de dois alunos de meios desfavorecidos, que receberam bolsas de estudo.

No rol das 34 escolas freqüentadas, todas pertencentes à rede privada, encontramos uma grande variedade de estabelecimentos: escolas de prestígio reconhecido na cidade (duas confessionais e uma leiga); escolas confessionais tradicionais que já ocuparam uma posição destacada no passado, caracterizando-se hoje como típicas escolas de bairro freqüentadas pelos moradores do entorno; escolas ditas "alternativas" (duas); escolas mais recentes, não confessionais cuja reputação se baseia em sua suposta eficácia pedagógica; escolas reconhecidas pelo baixo prestígio acadêmico. Nesse leque extremamente diversificado, deve ser assinalado o fato de que dos 32 alunos, cerca de 30\% freqüentaram uma outra escola confessional.

Se à primeira vista essa informação pode sugerir que os pais têm como objetivo a educação religiosa para seus filhos, as representações tecidas por coordenadoras da escola, quando entrevistadas, vêm afastar esse tipo de projeto e confirmar os achados do estudo realizado em 1975, por Merakchi junto aos pequenos comerciantes:

.... que se vem constatando é que a demanda dos pais é menos por uma formação religiosa propriamente dita do que por um ambiente asséptico e tranqüilizador numa demonstração de que a catequese vem sendo passada para segundo plano, em favor de preocupações de ordem moral e disciplinar. Em segundo, a necessidade de remediar danos causados por fracassos escolares anteriores (ou até mesmo preveni-los quando já são pressentidos) conduz também as famílias a buscar refúgio em certos estabelecimentos privados que se encarregam de acolher jovens com dificuldades escolares, oferendo-Ihes maiores chances de reintegração às fileiras nobres do sistema escolar." (apud Nogueira, 1991, p.99) 
No contexto de fluxos não lineares, uma escola confessional pode significar acolhimento, uma possibilidade desses adolescentes viverem a experiência escolar de maneira mais serena, especialmente na relação tecida com a avaliação.

Mas há um outro dado que merece ser refletido: em que pese a heterogeneidade de projetos educativos expressos na variabilidade dos estabelecimentos de ensino, as famílias têm em comum a busca pelo atendimento às necessidades de seus filhos, bem como uma preocupação pragmática com os resultados dos investimentos feitos diante do futuro de seus filhos, visto hoje como incerto em termos da manutenção/melhoria da posição ocupada ontem pelos pais no espaço social.

\section{O ESTUDO NA VIDA DO ESTUDANTE}

Existe já um razoável consenso entre nós sobre a importância da realização do dever de casa na formação do hábito de estudo e seus desdobramentos sobre o desempenho dos estudantes. Entretanto, ainda sabemos muito pouco sobre os modos pelos quais os estudantes se relacionam com as tarefas escolares, com os trabalhos feitos em casa, que remetem, em última análise, aos sentidos imprimidos pelos alunos à experiência escolar e que variam segundo a origem social, as estratégias educativas dos pais, ao ethos do estabelecimento escolar, aos estilos de trabalhar dos professores.

Nessa fase da vida do adolescente, Dubet e Martuccelli (1996) afirmam que se assiste a emergência de uma série de estratégias, e que o aluno adota a linguagem do cálculo e dos investimentos planejados. Para esses autores, o sentido do estudo se separa da pura lógica de integração escolar e de identificação com o professor, própria das primeiras séries do ensino fundamental e passa a se apoiar fragilmente entre duas matrizes: a utilidade do diploma e o interesse intelectual.

Em que pese a percepção da rentabilidade dos estudos ser heterôgenea e variar segundo os públicos sociais, tanto a utilidade do valor do diploma como a vocação para um determinado campo de estudos é volátil nesse ciclo da vida e correm ao sabor de resultados escolares e mediante o contato com as disciplinas. As forças próprias que animam, mobilizam o estudante para o estudo ainda parecem ser exteriores ao trabalho escolar e basear-se no sistema de 
O significado da experiência...

recompensas, de encorajamento, seja por parte dos pais ou mesmo pelos professores, segundo Dubet e Martuccelli.

Embora em nossa pesquisa não tenhamos perseguido o objetivo de mapear a utilidade do diploma e o interesse por algum campo de estudo entre estudantes das camadas médias, emergiu com força o lugar que o estudo tem em suas vidas tanto do ponto de vista das condições materiais para a constituição da disposição do estudo oferecidas pelas famílias como dos cálculos acionados para a racionalização e otimização de seus desempenhos escolares

Senão vejamos: $85 \%$ dos alunos afirmaram possuir mesa de estudo e $65 \%$ e 58\% respectivamente computador e internet em seu quarto, além de vários outros equipamentos como a televisão, o telefone, o vídeo etc. Isso significa que as famílias disponibilizaram condições materiais adequadas para o estudo dos filhos e, mais, expressaram a importância conferida aos processos de escolarização por esse segmento.

Quando passamos às respostas dadas pelo grupo às tarefas escolares, identificamos algumas estratégias de conduta dos adolescentes: 85\% afirmaram fazer o dever de casa em geral quando essa tarefa vale nota, sendo o envolvimento com as atividades quase sempre condicionado pelo número de pontos que vale tal ou qual exercício arbitrado pelo professor, o que, por sua vez, irá gerar uma série de outras estratégias. Entre elas estão o estabelecimento de prioridades (algumas atividades valem mais do que outras e são mais valorizadas) e a realização de um "mínimo necessário" em termos de resposta às exigências acadêmicas, o que foi assinalado por alguns dos coordenadores entrevistados

Perguntados se estudam para os testes e provas marcados pela escola, $46 \%$ dos alunos afirmaram estudar apenas para as disciplinas em que estão com nota baixa e 50\% afirmaram estudar e se preparar sozinhos "apenas" na véspera do dia marcado para a avaliação.

A esse dado acrescente-se que $73 \%$ dos alunos afirmam não realizar, às vezes, a tarefa solicitada, 38\% copiam dos colegas em algumas ocasiões, o que pode remeter para o fato de que o ofício de aluno de camadas médias comporta uma "eficácia" que se expressa nas jogadas efetuadas, nos cálculos que precisam ser feitos e que variam em razão do efeito - professor (estilo de trabalhar, maior ou menor cobrança acadêmica) e dos recursos que possam auferir diante da realização da tarefa. 
Trabalhando sobre o tema da fabricação da excelência escolar, Perrenoud analisa os mecanismos apreendidos pelo aluno para ter sucesso na escola e corrobora os nossos achados. Para o autor, "a preparação intensiva para o exame é também um trabalho, talvez até mais fastidioso, mas bem mais econômico para quem compreendeu o sistema"( 1994, p. 139). Em sua crítica às atitudes estereotipadas do ensino, o autor chama a atenção para a relação estratégica com a avaliação, que leva o aluno a tirar partido de todos os recursos que a situação the oferece. Entrando no "jogo", caberá a ele administrar os "sinais exteriores" da competência que está sendo avaliada, seja preparandose na última hora ou salvando apenas as aparências, seja trabalhando intensamente. De um modo ou de outro, o autor chama a atenção para um saber fazer, um habitus que ajuda o aluno a demonstrar outros saberes, outras competências instrumentais, tão necessárias quanto os conteúdos de ensino, "seja para demonstrar, valorizar ou manifestar através da palavra o que se sabe, seja para negociar a avaliação com o professor"(p. I40).

Quando perguntados se recorrem à ajuda da família, uma parte significativa afirmou estudar sozinha sempre (58\%), enquanto 62\% estudam com colegas considerados bons na matéria e $58 \%$ buscam amigos para dar conta das tarefas. Foi expressivo o fato de $62 \%$ terem afirmado não estudar com a mãe ou o pai. Isso pode indicar a existência de uma série de mecanismos: falta de disponibilidade dos pais para acompanhamento do cotidiano escolar do fiIho diante da sobrecarga de trabalho dos setores médios; presença da estratégia do cálculo no ofício do aluno, no recurso ao colega, um bom aluno; presença de habitus escolar, construído no interior da família, próprio de setores que priorizam o produto final e não os processos de aprendizagem.

Considerando que o tempo gasto com o estudo expressa uma relação com a escola e com a aprendizagem dos conteúdos cognitivos, os dados sugerem, à primeira vista, que os estudos para a maioria dos alunos não chegam a comprometer o cotidiano de sua vida de adolescente: $73 \%$ dos alunos utilizam-se de uma a três horas por semana para o estudo, passando a $23 \%$ aqueles que gastam de três a cinco horas semanais. Do mesmo modo, se interrogados sobre o estudo nos finais de semana, 62\% afirmaram estudar apenas algumas vezes, enquanto 12\% afirmaram estudar quase sempre.

Diante desse quadro, valeria perguntar: tornaram-se esses estudantes "profissionais" na arte de driblar as demandas escolares? São blasés diante dessa escola por vê-la como instituição pouco rigorosa do ponto de vista das exigên- 
cias escolares? É próprio da adolescência das camadas médias uma relação pouco laboriosa com o estudo?

Parece que uma das respostas a essas perguntas pode estar em uma relação com a experiência escolar menos tensa, mais instrumental, própria de uma geração bombardeada pelos meios de comunicação e informação, os quais por sua vez se investem também de um suposto papel pedagógico e que coloca para a escola a necessidade de buscar definir melhor a especificidade da prática pedagógica para estes tempos (Fischer, 1999, p.29).

Para Sarlo, nesta sociedade de consumo, a escola vive um dilema pois a cultura juvenil

...construiu-se no marco de uma instituição tradicionalmente consagrada aos jovens que está em crise: a escola, cujo prestígio se debilitou tanto pela queda das autoridades tradicionais quanto pela conversão dos meios de massa no espaço de uma abundância simbólica que a escola não oferece. (2000, p.39)

No espaço de uma abundância simbólica oferecida pela televisão e demais meios de comunicação, o aluno precisa dar conta, ao mesmo tempo, de duas lógicas: a lógica escolar, marcada pelo esquadrinhamento do tempo, pela centralidade da cultura escrita, pela separação das disciplinas escolares em um cenário lento e contínuo e a lógica midiática, marcada pelo imediatismo, pela instantaneidade, pela rapidez e descontinuidade das informações.

Isso parece ser evidente quando verificamos que $70 \%$ dos alunos realizam o dever de casa (quase sempre ou algumas vezes) assistindo televisão, o que remete à "dispersão" como traço distintivo dos comportamentos diante das práticas escolares.

Essa dispersão pode representar uma outra forma de se relacionar com o saber e a aprendizagem escolar, para além dos métodos pedagógicos e estilos de ensinar dos professores como bem analisaram Oliveira e Mattos (2003). Trabalhando sobre a perspectiva de uma geração zapping, como diria Sarlo (2000), Mendes de Almeida e Tracy vêm complementar nossos achados:

A geração zapping - definida pelos especialistas como aquela que vive mudando de canal o tempo todo - é emblemática dessas novas manifestações. Importa chamar a atenção, aqui, para o fato de que tanto a mídia atual quanto os especialistas vêm apontando a particular aptidão dos jovens de classe média dos gran- 
des centros urbanos de fazer uso simultâneo de dispositivos eletrônicos, tais como telefone celular, computador, som e TV. O uso simultâneo desses recursos também se estende à realização de tarefas e obrigações que exigem concentração, como estudar. Neste sentido, podemos fazer referência, no âmbito das culturas jovens, a formas de atenção e de concentração de pensamento que se processam independentemente de vivências seqüenciais e lineares. (2003, p.68)

Se essas disposições diante das tarefas escolares marcadas por comportamentos estratégicos podem, à primeira vista, sugerir que os estudantes investigados rejeitam a prática da leitura ou têm com ela uma relação de pouca familiaridade, consumidores que são em larga escala da mídia e de outros meios de comunicação de massa, os dados obtidos pelo questionário sinalizaram alguns aspectos significativos: 62\% rejeitaram a imagem de que ler é uma perda de tempo, o que não significa que seja uma de suas distrações preferidas. Mas foi também sugestivo o fato de que $69 \%$ dos alunos tenham afirmado que "só lêem quando é necessário", revelador da linguagem do cálculo, presente também na realização do dever de casa.

Quando indagados sobre o que lêem, as informações obtidas indicaram que o que os jovens lêem quase sempre são e-mails e sites (58\%), seguidos de jornais (50\%) e revistas (38\%). Com freqüência bem mais baixa, encontramos uma preferência por livros de ficção entre $23 \%$ dos alunos, seguida de não ficção (19\%) e poesia, o gênero nunca lido por 62\% dos estudantes.

Algumas questões merecem nossa reflexão: a primeira delas refere-se à rapidez na conquista de informação que os jornais e os e-mails, como suportes de leitura, garantem aos jovens das camadas médias, diferentemente da cultura letrada dos livros. Em relação à leitura do texto eletrônico, Chartier afirma que faltam estudos sobre seus usos, suas práticas, seus impactos sobre as tarefas, sobre o trabalho, mas que, sem dúvida alguma, a composição eletrônica é difundida sem mediações, sem intermediários, podendo o leitor transformar imediatamente o texto recebido por um autor (200 I, p. I53).

Por esta via, a leitura de e-mails e sites pode significar o acesso a um mundo sem fronteiras, onde o estudante - leitor pode ler e refazer o texto com uma liberdade que não existe no livro ou texto didático, transformando-se simultaneamente em autor. 
O significado da experiência...

A segunda questão refere-se ao fato de que ler um e-mail, site, jornal ou revista implica um grau diverso de internalização do mundo social, conforme Chartier (200l). Essa leitura talvez não seja tão constrangedora se a compararmos, por exemplo, à de um livro didático, ou mesmo paradidático.

Considerando que a lógica da escola está fundada no desenvolvimento intelectual de longa concentração e não se reutiliza das habilidades de leitura adquiridas pelos alunos nos suportes de leitura como e-mails, jornais revistas, somos tentados a interrogar a escola sobre os usos que faz do texto eletrônico, do jornal e das revistas, muito lidos pelos adolescentes no ofício construído como estudantes.

\section{FORA DA ESCOLA, O QUE FAZEM OS ESTUDANTES?}

Analisando a adolescência do ponto de vista do tempo, Melucci afirma que mais do que uma condição biológica, a juventude começa a coincidir com a suspensão de um compromisso estável, com um tipo de aproximação nômade em relação ao tempo, espaço e cultura. A cultura juvenil expressa-se em estilos de roupa, gêneros musicais, participação em grupos, os quais funcionam como linguagens temporárias e provisórias com as quais o indivíduo se identifica e manda sinais de reconhecimento para outros. Para o autor, a vida social é hoje dividida em múltiplas zonas de experiência, cada qual caracterizada por formas específicas de relacionamento, linguagem e regras. Esse excesso de possibilidades que a cultura engendra amplia o limite do imaginário e incorpora ao horizonte simbólico regiões inteiras de experiência que foram previamente determinadas por fatores biológicos, físicos ou materiais. Nesse sentido, a experiência é menos transmitida e cada vez mais uma realidade construída com relacionamentos e representações: menos algo para se "ter" e mais algo para se "fazer"( 1997, p.9).

No caso dessa pesquisa, em que pese a afirmação de algumas professoras de que a agenda de seus alunos está mais vazia do ponto de vista de atividades extra-escolares, a realidade que encontramos nas respostas dadas ao questionário pelos adolescentes contraria as representações tecidas pelas entrevistadas: o tempo do estudante fora do tempo da escola é usado em múltiplas zonas de experiência, todas elas plenas de redes de sociabilidade e de circulação social. Assim, vamos encontrar em dados percentuais, a maioria de 
alunos (65\%) freqüentando cursos de línguas estrangeiras, seguida por $46 \%$ fazendo alguma atividade de esporte. Essa experiência longe de ter um caráter aleatório evidencia a presença de uma estratégia desenvolvida pelas elites e camadas médias para transmitir a seus filhos um tipo de capital cultural, importante indicador de distinção social. O resultado é um bom domínio do inglês para $31 \%$ dos pesquisados e razoável para 58\%. Para uma parcela de alunos, tanto o francês como o espanhol também são de domínio razoável. Essa situação é compreensível pois quando perguntados sobre viagens ao exterior foi significativo o fato de $46 \%$ dos estudantes terem viajado para o exterior nos últimos três anos, sendo o destino mais freqüente a América do Norte, seguida de países da Europa como Inglaterra, França e Espanha.

Quando passamos ao lazer, verificamos que no Rio de Janeiro, a praia ainda é o lugar que reúne a maioria dos adolescentes (65\%), seguida do shopping (62\%) e cinema (50\%). Com alguma freqüência, vamos encontrar $50 \%$ de alunos freqüentando museus e galerias de arte, 54\% indo a shows, $54 \%$ a teatros e $50 \%$ a eventos esportivos. Como dados sugestivos, encontramos alta percentagem de alunos que nunca vão à ópera e balé (69\%), a cibercafé ou casa de jogos eletrônicos (73\%).

Com relação a shoppings como um dos lugares mais procurados pelos nossos alunos, uma explicação pode estar no seu caráter extraterritorial e "transocial", características que fascinam e justificam a sua alta freqüência pelos jovens, exatamente pela possibilidade de oferecimento de uma cenografia riquíssima na qual nada falta, sendo uma exposição de todos os objetos sonhados. Nele, "o mercado" potencializa a liberdade de escolha (mesmo que isso seja só uma tomada de partido imaginária), educa em saberes que são, por um lado, funcionais em sua dinâmica e, por outro, adequados ao desejo juvenil de liberdade antiinstitucional (Sarlo, 2000, p.2 I). Ora, na medida em que as instituições tradicionais já não podem construir marcos que se pretendam eternos, erige-se um monumento baseado justamente na velocidade de fluxos, de torrentes de significantes.

Com relação aos programas de televisão, destaca-se o número alto de alunos que quase sempre vê filmes e seriados (73\%), shows e musicais (62\%), programas de humor (73\%), jornais e noticiários (50\%).

O que sugerem esses dados? Quais os impactos sobre o sentido de viver a escola e o ofício de aluno? 
Em primeiro lugar, podemos afirmar, concordando com Melucci, que adolescentes constroem a sua experiência de uma forma mais fragmentada, pois pertencem a uma diversidade de redes e de grupos: grupo familiar, grupo dos colegas da escola, grupo dos colegas de cursos livres, redes de amigos. Entrar e sair dessas diferentes formas de participação é mais rápida e mais freqüente do que antes e o tempo que os adolescentes investem em cada uma delas é reduzido. Além disso, continua Melucci, os meios de comunicação, o ambiente educacional, as relações interpessoais, o lazer e o tempo de consumo geram mensagens para os indivíduos que por sua vez são chamados a respondêlas com outras mensagens. $\bigcirc$ passo da mudança, a pluralidade das participações, a abundância de possibilidades e mensagens oferecidas aos adolescentes contribuem todos para debilitar os pontos de referência sobre os quais a identidade era tradicionalmente construída (1997, p. |0).

Isso significa que a escola, antes núcleo fundamental de construção de identidade para o adolescente pode estar, a seus olhos, sendo deslocada, desintegrada como instância de socialização "pois a unidade e continuidade da experiência individual não podem ser encontradas com um modelo, grupo ou cultura definidos" (Melucci, 1997, p. II).

Em segundo lugar, o fato de o adolescente estar imerso em várias redes de circulação social pode fomentar uma relação de dispersão diante do mundo, própria de um tempo que não se repete nunca e que vai exigir contatos imediatos e intuitivos com a realidade, fora do confinamento dos rígidos limites de um pensamento racional, próprio da instituição escolar. Quem sabe não é a dispersão uma nova capacidade manifestada pelo aluno de lidar com uma abundância de canais de comunicação?

Em terceiro lugar, a geração do zapping obriga-nos a pensar na relação entre a cultura da mídia e a escolarização, para além da cultura escrita. Para Green e Bigum, essa mudança implica investir no conhecimento do currículo e da alfabetização sob novas bases, até porque uma subjetividade pós-moderna está em curso "compreendendo uma efetivação particular da identidade social e da agência social, corporificadas em novas formas de ser e tornar-se humano"( 1995, p.2 |4). Problematizando a qualificação conferida aos jovens como "alienígenas", alienados no sentido clássico, os autores criticam o olhar preconceituoso das gerações mais velhas sobre a juventude e sobre a mídia e solicitam pesquisas que possam avançar a relação entre currículo e escolariza- 
ção, fora dos marcos da pedagogia tradicional. Por essa via, a mídia eletrônica de massa está centralmente implicada como contexto socializador crítico e coloca a necessidade de se analisar pedagogias exteriores à instituição escolar.

De um modo ou de outro, o que esses autores buscam é o entendimento de que pensar o ofício do aluno à luz dos meios de comunicação de massa implica desconstruir certezas e especialmente considerar um complexo de forças que atuam sobre a construção da identidade.

Finalmente, essas novas referências vêm interrogar sobre as práticas culturais tradicionalmente identificadas com as camadas médias e, nelas, o lugar ocupado pela chamada alta cultura ou cultura letrada. À luz dos dados obtidos, o que fica evidente é que a mídia e os demais meios de comunicação de massa parecem ser os canais de informação desse grupo com impactos na forma pela qual o aluno se relaciona com o tempo, fora e dentro da escola.

\section{UMA PERSPECTIVA A PERSEGUIR}

A partir do quadro mapeado, é possível levantar algumas questões que podem ajudar a compreender melhor o jovem de camadas médias na realização de seu ofício de estudante.

A primeira delas refere-se à necessidade de aprofundamento do que significa a experiência escolar e, especialmente, do lugar ocupado hoje pela escola ao lado de outras instituições sociais. Em "O declíneo da instituição", Dubet (2002) alerta para o fato de que, na pós-modernidade, os atores são confrontados a lógicas contraditórias e devem se situar dentro de racionalidades plurais: a da cultura da produção, da cidadania, das múltiplas identidades... $\bigcirc$ indíviduo torna-se "incerto", fragmentado, constrangido a gerir lógicas opostas e o sujeito não está mais enraizado em um conjunto homogêneo de valores e de identidades. Ele está descentrado e partido. Para o autor, a ação explicaria menos pela necessidade de socialização do que pela economia das "razões práticas" ou das "boas razões" que remetem aos mecanismos cognitivos e às lógicas de comunicação contextualizada.

Ora, é este o indivíduo encontrado por nós na pesquisa: o aluno que é econômico na realização da atividade escolar, o aluno estrategista que usa o tempo com base no trabalho que precisa efetuar e que o faz com a lógica de "um mínimo necessário a um desempenho satisfatório", independentemente do es- 
tilo de ensinar "do" professor, da maior ou menor afinidade com uma disciplina.

Longe de realizar uma leitura negativa do tipo "o fim da escola", essa característica nos provoca a pensar sobre o ofício a partir de outras referências não estritamente escolares mas próprias de um tempo em que o ator não é mais o "sistema".

Explicando melhor, hoje mais do que nunca, as instituições, nela, a escola, perderam o charme (Dubet, 2002), exigindo um trabalho de justificação permanente, que se assenta muito mais sobre o carisma pessoal do que sobre as competências técnicas dos profissionais. No quadro de uma sociedade em que o ator se separa do sistema, mais o indivíduo social e o sujeito se distinguem, e a motivação aparece mais como um problema que requer dos professores um conjunto de atributos de diversas naturezas.

Nesse contexto, o que significa ser um "bom" e um "mau" aluno? Um estudante que acata a disciplina, que reage às exigências acadêmicas de forma obediente ou um aluno que, conhecendo as regras do jogo escolar, efetua jogadas (apoiado e até estimulado pelas famílias) movido por "razões práticas" de que falava Dubet (2002), tendo em vista sair-se bem com o mínimo de esforço para logo, logo, de forma motivada, entrar na internet ou assistir um filme na televisão?

Mais do que responder a pergunta, é nossa intenção avançar sobre as novas subjetividades dos jovens, "nômades" I por excelência, para, aprendendo com elas, poder pensar uma escola mais sintonizada com a cultura juvenil.

Considerando que não poderíamos ter a pretensão de esgotar as questões sobre o ofício do estudante das camadas médias, o que a pesquisa provocou foi a necessidade de continuar investindo em estudos a partir de uma leitura positiva sobre o jovem, a mídia e a experiência escolar fora do paradigma da escola republicana, centrada unicamente nos conhecimentos escolares, na autoridade e na disciplina. E mais, que a pesquisa sobre a escolarização das camadas médias é um objeto que exige o movimento de pensar em uma pluralidade de estilos de vida e de gostos, de valores que vão além dos volumes e estruturas de capital econômico e cultural desses grupos sociais.

I I. Expressão cunhada por Almeida e Tracy (2003) para mostrar como a mobilidade dos jovens nas noites cariocas é um comportamento sintomático dos seus sucessivos deslocamentos em outros campos do cotidiano 


\section{REFERÊNCIAS BIBLIOGRÁFICAS}

ALMEIDA, M. I. M. de; TRACY, K. M. A. Noites nômades : espaço e subjetividade nas culturas jovens contemporâneas. Rio de Janeiro: Rocco, 2003.

BOURDIEU, P. Razões práticas sobre a teoria da ação. São Paulo: Papirus, 1997.

CHARTIER, R. Cultura escrita, literatura e história. Porto Alegre: Artmed, $200 \mathrm{I}$.

DUBET, F; MARTUCCELLI, D. A L'École sociologie de l'expérience scolaire. Paris: Seuil, 1996.

DUBET, F. Le Déclin de l'institution. Paris: Seuil, 2002.

FISCHER, R. M. Identidade, cultura e mídia: a complexidade de novas questões educacionais na contemporaneidade. In: SILVA, L. H. da (org.) Século XXI : qual conhecimento? qual currículo? Petrópolis: Vozes, 1999. p. 18 -32.

GREEN, B.; BIGUM, C. Alienígenas na sala de aula. In: SILVA, T. da (org.) Alienígenas na sala de aula : uma introdução aos estudos culturais em educação. Petrópolis: Vozes, 1995. p.208-243.

MELUCCI, A. Juventude, tempo e movimentos sociais. Revista Brasileira de Educação, São Paulo, n.5/6, p.5-14, maio/dez. 1997.

NOGUEIRA, M. A. Famílias de camadas médias e a escola: bases preliminares para um objeto em construção. Educação e Realidade, Belo Horizonte, v.20, n. I , p.9-25, jan./ jun. 1995.

Trajetórias escolares, estratégias culturais e classes sociais: notas em vista da construção do objeto. Teoria e Educação, Porto Alegre, n.3, p.89- | 12, 199 | .

OLIVEIRA, C.; MATTOS, L. O. A Dispersão como elemento constituinte das práticas pedagógicas. Rio de Janeiro, jul. 2003. (mimeo)

PERRENOUD, P. O Ofício do aluno e o sentido do trabalho escolar. Porto: Porto Editora, 1994.

ROMANELLI, G. Questões teóricas e metodológicas nas pesquisas entre famílias e escola. In: ZAGO, N.; CARVALHO, M. P.; VILELA, R. A. Itinerários de pesquisa: perspectivas qualitativas em sociologia da educação. Rio de Janeiro: D.P. \& A., 2002. p.245-264.

SARLO, B. Cenas da vida pós-moderna: intelectuais, arte e videocultura na Argentina. Rio de Janeiro: Editora UFRJ, 2000.

Recebido em: outubro 2003

Aprovado para publicação em: fevereiro 2005 